\title{
Ultrasensitive single-genome sequencing: accurate, targeted, next generation sequencing of HIV-1 RNA
}

Valerie F. Boltz ${ }^{1 *}$, Jason Rausch', Wei Shao ${ }^{2}$, Junko Hattori ${ }^{1}$, Brian Luke², Frank Maldarelli ${ }^{1}$, John W. Mellors ${ }^{3}$, Mary F. Kearney ${ }^{1}$ and John M. Coffin ${ }^{4}$

\begin{abstract}
Background: Although next generation sequencing (NGS) offers the potential for studying virus populations in unprecedented depth, PCR error, amplification bias and recombination during library construction have limited its use to population sequencing and measurements of unlinked allele frequencies. Here we report a method, termed ultrasensitive Single-Genome Sequencing (USGS), for NGS library construction and analysis that eliminates PCR errors and recombinants, and generates single-genome sequences of the same quality as the "gold-standard" of HIV-1 single-genome sequencing assay but with more than 100-fold greater depth.

Results: Primer ID tagged CDNA was synthesized from mixtures of cloned BH10 wild-type and mutant HIV-1 transcripts containing ten drug resistance mutations. First, the resultant CDNA was divided and NGS libraries were generated in parallel using two methods: USGS and a method applying long PCR primers to attach the NGS adaptors (LP-PCR-1). Second, CDNA was divided and NGS libraries were generated in parallel comparing 3 methods: uSGS and 2 methods adapted from more recent reports using variations of the long PCR primers to attach the adaptors (LP-PCR-2 and LP-PCR-3). Consistently, the uSGS method amplified a greater proportion of CDNAs, averaging 30\% compared to $13 \%$ for LP-PCR-1, 21\% for LP-PCR-2 and 14\% for LP-PCR-3. Most importantly, when the uSGS sequences were binned according to their primer IDs, $94 \%$ of the bins did not contain PCR recombinant sequences versus only 55,75 and 65\% for LP-PCR-1, 2 and 3, respectively. Finally, when USGS was applied to plasma samples from HIV-1 infected donors, both frequent and rare variants were detected in each sample and neighbor-joining trees revealed clusters of genomes driven by the linkage of these mutations, showing the lack of PCR recombinants in the datasets.
\end{abstract}

Conclusions: The uSGS assay can be used for accurate detection of rare variants and for identifying linkage of rare alleles associated with HIV-1 drug resistance. In addition, the method allows accurate in-depth analyses of the complex genetic relationships of viral populations in vivo.

Keywords: HIV, Single-genome sequencing, SGS, Primer ID, Supermajority correction, Allele linkage, Targeted nextgeneration sequencing, NGS, Deep sequencing, Minority variants, HIV drug resistance

\section{Background}

Next generation sequencing (NGS) has the potential to become a powerful tool for studying the genetics of viral RNA populations from cDNA libraries generated by

\footnotetext{
*Correspondence: boltzv@mail.nih.gov

${ }^{1}$ HIV Dynamics and Replication Program, CCR, National Cancer Institute, $\mathrm{NIH}$, Translational Research Unit, 105 Boyles Street, Building 535 Room 111, Frederick, MD 21702-1201, USA

Full list of author information is available at the end of the article
}

RT-PCR. To date, its application to targeted sequencing of diverse HIV-1 or other viral RNA populations has been limited by PCR error, unequal amplification of sequences (PCR bias), and PCR recombination during library construction. It is known that polymerase mis-incorporation errors accumulate during PCR [1-4] requiring the use of sophisticated statistical algorithms of variable accuracy [5-7] to distinguish errors from actual genetic polymorphisms. PCR bias occurs by selective or preferential 
amplification of some templates over others, limiting and misrepresenting the number of original distinct viral RNA templates represented in the final sequencing data [1-4]. Most importantly, PCR-mediated recombination can rearrange the sequences among amplicons producing variants or haplotypes that are not actually present in vivo $[2,8,9]$, and causing the loss of rare haplotypes through recombination between amplicons with wildtype alleles that dominant the PCR reaction. As such, PCR recombination not only skews population frequencies, but also limits the ability to detect linkage among rare genetic polymorphisms. Together, these problems have restricted the applicability of NGS for genetic analysis of HIV-1 or other viral populations causing it to fall short of replacing the "gold standard" of HIV-1 single-genome sequencing (SGS), which virtually eliminates PCR error, bias, and recombination but is constrained by the limited number of sequences that can be obtained easily [10-14].

To help address these issues, primer IDs, consisting of molecular tags comprising 4-10 degenerate nucleotides (nt), have been incorporated into RT primers so that each cDNA molecule generated by reverse transcription is uniquely labeled [1, 15-18]. Primer ID-tagged cDNAs are then replicated by PCR and daughter amplicons are sequenced by NGS. Next, binning sequence reads by their common primer IDs reveals PCR template resampling. In addition, the alignment of binned sequences facilitates the identification of PCR errors and PCR recombination such that one consensus sequence can be generated that is devoid of such artifacts. Although misincorporation errors within the primer ID itself during PCR can give misleading results, filtering techniques can be used to detect and exclude primer IDs with mis-incorporations [19]. As such, primer IDs are extremely effective in identifying errors introduced during NGS library generation and are the only means by which the number of amplified templates can be accurately determined; and, consequently, allele frequencies in HIV-1 RNA populations accurately measured.

During library generation, NGS requires the attachment of adaptor sequences for library capture, local amplification, and sequencing. Current methods to attach these adaptors employ PCR primers of varied length, ranging from $55[19,20]$ to as long as 92 nucleotides [21]. In addition, two [19] or three rounds of flanking PCR [20] are used to attached the requisite adaptors. One such "long primer PCR" method (LP-PCR-1) has been shown to produce very high levels of PCR recombination [21] such that the final results are unreliable for identifying rare mutations or for performing accurate analyses of population genetics. Newer methods for long primer PCR (LP-PCR-2 and LP-PCR-3) $[19,20]$ are improvements over LP-PCR 1, but as shown here, these methods can still cause loss of variants either due to PCR bias, error, and/or recombination. Accordingly, we developed a new method for NGS library construction called ultrasensitive single-genome sequencing (uSGS), which uses a unique method to attach the NGS adaptors to amplified templates that does not require additional PCR. The method combines limited-cycle PCR with a highly efficient method of adapter ligation. The uSGS method also amplifies a higher fraction of cDNA molecules than the LP-PCR methods, and significantly reduces the percentage of sequences that are lost from PCR errors and recombination. Data resulting from uSGS rivals the accuracy and reliability of the "gold standard" HIV-1 SGS assay (sometimes referred to as single genome amplification [SGA] and sequencing) but with more than 100-fold greater sequencing depth.

Here, we report a comparative analysis of uSGS and methods adapted from recent reports [2, 19-21] for targeted NGS library generation and show that USGS is a superior method for generating NGS datasets free of PCR error, and recombination. Although uSGS is described here for its utility in studying HIV-1 RNA populations, it can be easily modified to investigate other viral RNA populations as well as transcript sequences across cell types, including malignant cells.

\section{Experimental design}

Primer ID-tagged cDNAs were prepared from mixtures of wild-type (WT) and mutant transcripts derived from cloned BH10 HIV pol DNA. The mutant transcripts contained 10 well-characterized, HIV-1 drug resistance mutations rendering them useful for measuring recombination and allele frequencies. In our initial experiments, the cDNA was divided and amplified with 2 different methods, uSGS (Fig. 1a) and LP-PCR-1 (Fig. 1b). uSGS was performed with short (25-31nt) primers containing 4 or 5 deoxyuridine (dU) residues. The amplified products were subsequently treated with uracil DNA glycosylase (UDG) and alkali, leaving $~ 17$ nt single-stranded tails, permitting efficient directional ligation [22, 23] of Illumina adaptor sequences. LP-PCR 1 used long (93nt) primers to incorporate Illumina adaptor sequences in a single round of PCR. In subsequent experiments, the primer ID-tagged cDNAs mixtures were divided 3-ways and amplified by uSGS (Fig. 1a) or by LP-PCR-2 (Fig. 1c) and LP-PCR-3 (Fig. 1d), the latter two methods requiring 55-65nt primers to incorporate Illumina adapters. LP-PCR- 2 and 3 were performed using the reagents and conditions specified in the original publications [19, 20]. LP-PCR-2 required 2 rounds of PCR and LP-PCR-3 required 3 rounds. NGS libraries prepared by all methods were sequenced using paired-end MiSeq technology and raw sequencing reads were processed through 


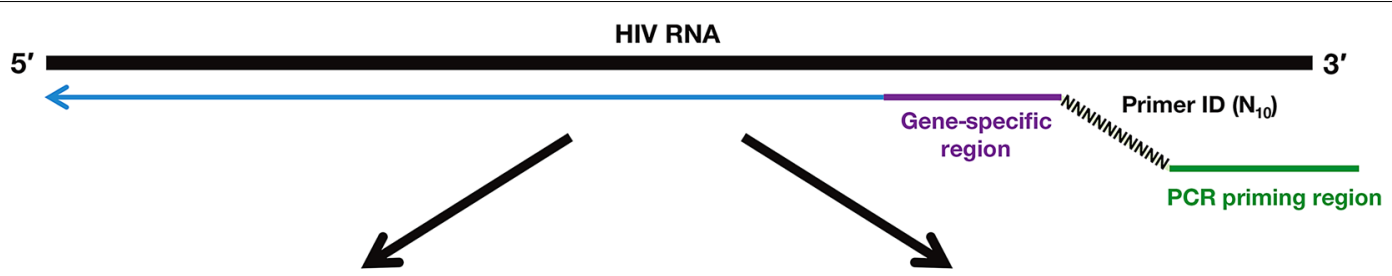

\section{a uSGS}

1. Amplify cDNA with short, dU-containing primers

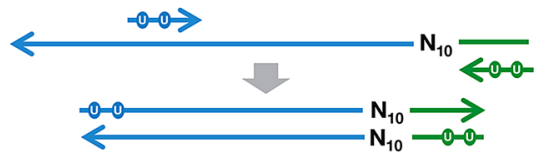

2. Remove uracils and cleave abasic sites

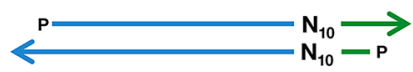

3. Ligate adapters and fill out recessed termini

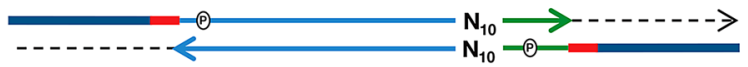

4. After purification, NGS library is ready for sequencing.

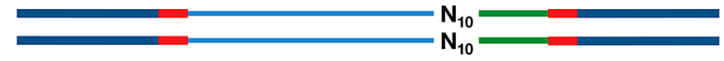

\section{Long Primer PCR-2}

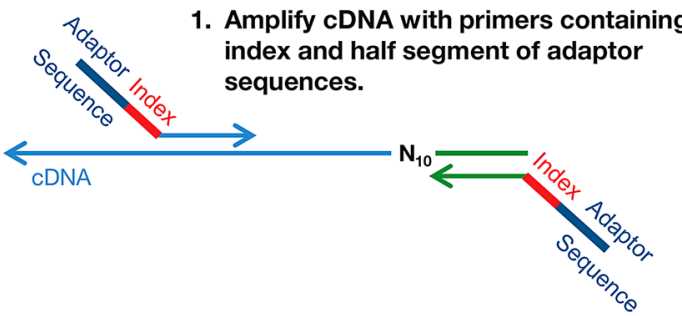

2. $2^{\text {nd }}$ round amplification with primers containing flanking segment of adaptor sequences.

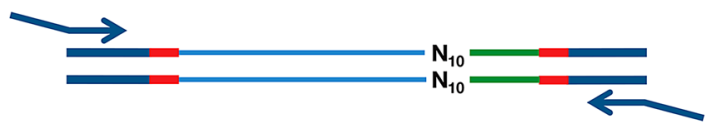

3. After purification, NGS library is ready for sequencing.

$$
\begin{aligned}
& \mathbf{N}_{10} \\
& \mathbf{N}_{10}
\end{aligned}
$$

b Long Primer PCR-1

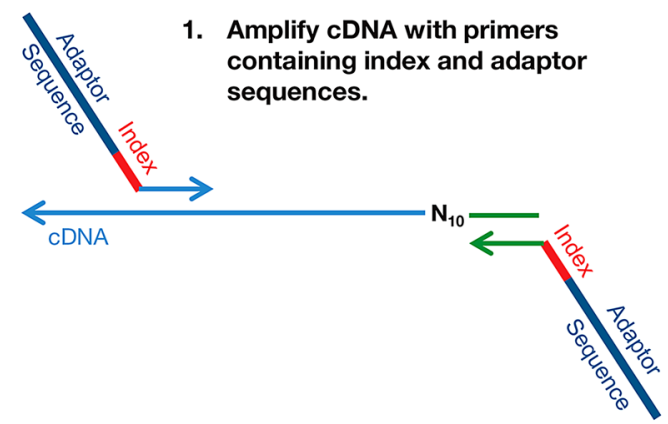

2. After purification, NGS library is ready for sequencing.

\section{d Long Primer PCR-3}

1. Amplify cDNA with short primers.
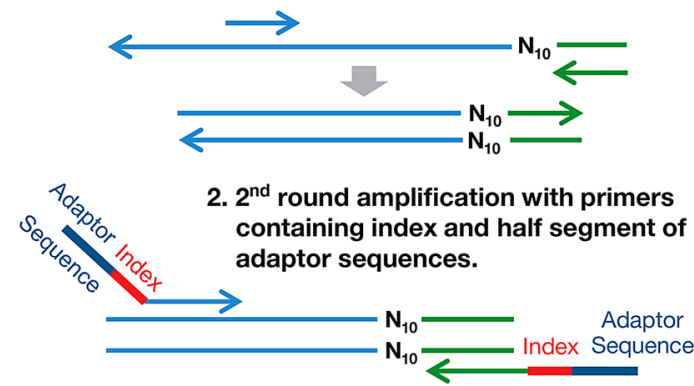

3. $3^{\text {rd }}$ round amplification with primers containing flanking segment of adaptor sequences.

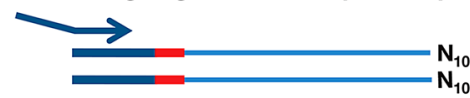

$\mathbf{N}_{10}$

4. After purification, NGS library is ready for sequencing.

$-N_{10}$
$-N_{10}$

Fig. 1 Schematic representation of the methods used for NGS library construction. A cDNA library labeled with Primer IDs (top) is divided and used for each method. a uSGS. Short PCR primers (25 and 31 bases) containing $5^{\prime} \mathrm{dU}$ in place of dT residues (dots in the primers) are used to amplify the CDNA. Products are cleaved at the dU sites creating dsDNA with 17-nt $3^{\prime}$-overhangs at both ends. The ends are then ligated to the essential NGS adapters and filled out using Klenow Fragment DNA polymerase to generate a fully double-stranded NGS library. b Long primer PCR-1. Long primers (90 and 93nt) containing NGS adapter sequences are used to amplify the cDNA library. c Long primer PCR-2. Relatively long primers (50-61 nt) are used in 2 rounds of flanking PCR to amplify the CDNA and attach the adaptors. $\mathbf{d}$ Long primer PCR-3 involves 3 rounds of PCR. The CDNA is amplified with short primers ( 25 and 31 bases) followed by 2 rounds of flanking PCR using long primers (50-61nt) to attach the adaptors 
the analytical pipeline described in Methods. Briefly, sequence reads from samples were separated according to their indexes and binned by common primer IDs. "Super-consensus" sequences were built from "qualified" unique primer ID groups resulting in a single-genome sequence per primer ID. To be qualified, a "super-consensus" sequence required two characteristics. First, it had to be derived from a set of common primer IDs that satisfied the cutoff model designed by Zhou et al. [19]. Zhou et al. [19] showed that low abundance primer IDs or "offspring" were artifacts resulting from PCR errors within the primer ID. To ensure that these artifacts were eliminated from the data, a cutoff model was designed for the minimum number of raw sequence reads required to make a consensus sequence. Second, we required "supermajorities" of $\geq 80 \%$ identity at each nucleotide position for a "super-consensus" sequence to be included in the dataset. We found that a simple majority (i.e., $>50 \%$ consensus at each nucleotide position) does not eliminate artifacts resulting from early-cycle PCR recombination or other PCR errors. In a simple majority, only late cycle PCR errors or late cycle recombinant events are eliminated. Accordingly, we increased the stringency of our filtering so that a "supermajority" of $\geq 80 \%$ identical bases at each nucleotide position would eliminate early PCR cycle errors and recombinants. To illustrate our findings, we analyzed the mixtures of WT and mutant transcripts at majority cutoffs of $50-100 \%$ for the 10 HIV- 1 drug resistance sites for each of the methods. Accordingly, if a final consensus sequence had a site of ambiguity, the sequence was discarded because this sequence contained either a PCR mis-incorporation error or a mixture of calls at the same site due to PCR recombination (or rare use of the same primer ID more than once). Final datasets for all the approaches were analyzed to compare (1) the fraction of the total cDNA molecules amplified efficiently, (2) the frequency of PCR/sequencing errors, (3) the level of PCR-based recombination, and (4) the sensitivity for detection of rare alleles.

\section{Results \\ PCR efficiency, and template sampling}

First, we compared amplification efficiency resulting from 3 independent experiments in which a single preparation of cDNA was synthesized using primer IDs, divided and used to compare the LP-PCR-1 and uSGS methods for NGS library generation. Table 1 tallies the average number of unique primer IDs containing the qualified number of raw sequences above the cutoff as defined by Zhou et al. [19]. The \% cDNA amplified was calculated by dividing the number of consensus sequences above the cutoff by the number of starting copies as measured by $\mathrm{qPCR}$, with averaging over 3 experiments. As shown in Table 1A, uSGS yielded more total unique primer IDs and more than twice as many consensus sequences compared to LP-PCR-1 (30 vs. 13\% of starting cDNAs, respectively). To further assess which method of library construction provided more complete sampling of the viral population, libraries were synthesized in 3 more replicate experiments in which a preparation of primer ID-tagged cDNA was divided into thirds and used to compare LP-PCR-2, LP-PCR-3, and uSGS methods (Table 1B). Ultrasensitive SGS generated greater than two-fold more consensus sequences than LP-PCR-3 (31 vs. $14 \%$ ) and 1.5-fold more sequences than LP-PCR-2 (31 vs. $21 \%)$.

Table 1 Comparison of cDNA amplification efficiency among methods using the same HIV-1 site specific RT-Primer ID primer

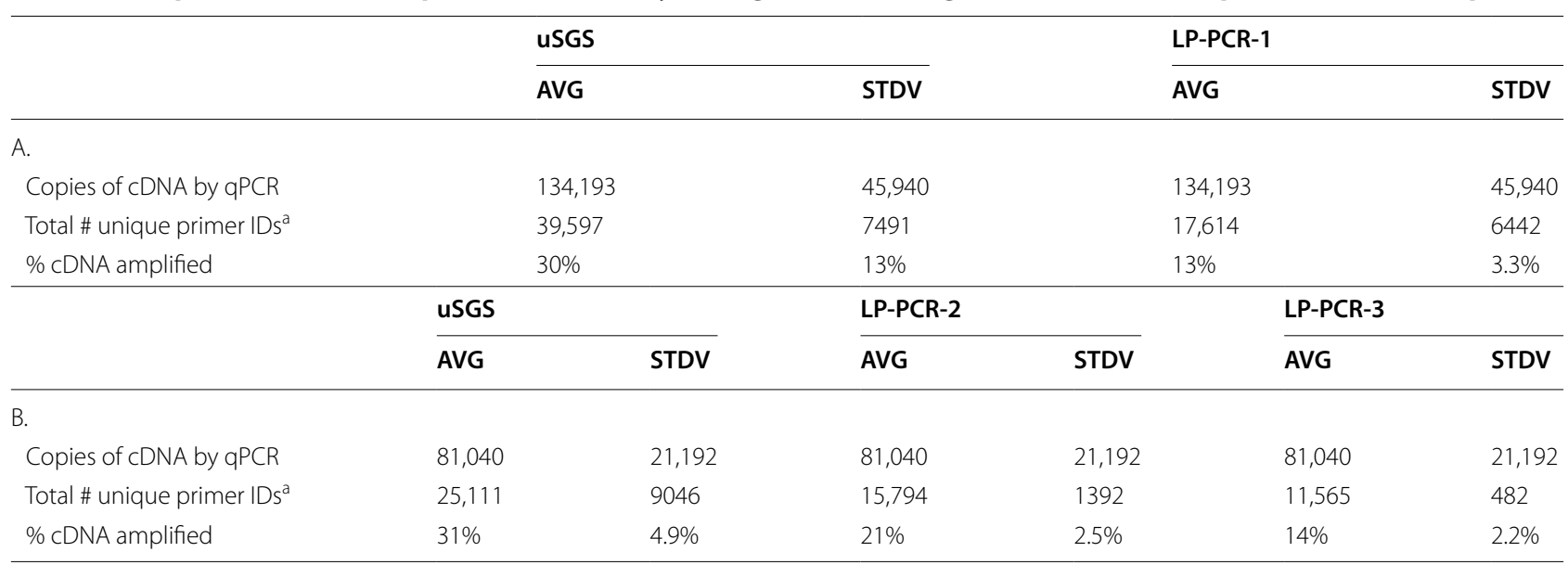

All results are taken from an average of 3 separate experimental libraries prepared from each method

a Total number of consensus sequences above the Zhou algorithm cutoff [19] 


\section{PCR and sequencing error rates}

Binning raw sequence reads by primer ID, generating alignments, and producing "supermajority" sequences ( $\geq 80 \%$ agreement at each site) resulted in PCR/sequencing error rates approximately 10 -fold lower than the uncorrected sequences regardless of the method used for generation of NGS libraries. Specifically, uncorrected $\mathrm{PCR} /$ sequencing error rates of $2.8 \times 10^{-3}$ and $1.6 \times 10^{-3}$ were calculated for raw sequence reads generated by LPPCR-1,2,3 and uSGS, respectively, values consistent with other reports [2, 24]. After applying the Zhou et al. [19] consensus cutoff model and generating the supermajority sequences from the alignments of reads sharing common primer IDs, the PCR/sequencing error rates were reduced to $1 \times 10^{-4}$ for uSGS, LP-PCR-1 and LP-PCR-3 and to $2 \times 10^{-4}$ for LP-PCR-2 (Table 2). These rates are comparable to those measured for standard SGS and the basal rate of $1 \times 10^{-4}$ mutations per base per cycle reported for HIV-1 reverse transcriptase in vitro [25], indicating that PCR and sequencing errors were essentially eliminated by the inclusion of primer IDs and the generation of supermajority sequences by our pipeline. Furthermore, in a separate experiment using 100\% WT transcripts, we found that the $\mathrm{PCR} /$ sequencing error rate was approximately the same $-5 \times 10^{-5}$-at all sites in the 500 base pair amplicons indicating that $\mathrm{PCR} /$ sequencing errors do not occur at higher rates at the drug resistance sites and that no false positive calls for drug resistance mutations occurred.

\section{PCR-mediated recombination}

Given that low frequency alleles can be missed and linkage eliminated by PCR recombination, we assessed its extent using all 4 methodologies. Primer ID tagged cDNAs were generated from mixtures of mutant and WT BH10 HIV-1 pol transcripts and NGS libraries were prepared. NGS libraries were sequenced, reads binned by primer ID, consensus cutoffs of $>50, \geq 60, \geq 70, \geq 80, \geq 90$

Table 2 Comparison of Recombination between methods at different consensus majority cutoffs in mixtures of BH10 WT and mutant transcript RNA

\begin{tabular}{|c|c|c|c|c|c|c|}
\hline$\%$ Majority cutoff & $\begin{array}{l}\text { Method/ } \\
\text { enzyme }\end{array}$ & Total sequences & $\begin{array}{l}\text { \% Sequences } \\
\text { excluded }^{\mathrm{a}}\end{array}$ & $\begin{array}{l}\% \text { Sequences } \\
\text { remaining }\end{array}$ & $\begin{array}{l}\% \text { Remaining recom- } \\
\text { binants missed }\end{array}$ & \% Errorb \\
\hline 50 & USGS & 33,870 & 0.6 & 99.4 & 0.39 & 0.020 \\
\hline 60 & & 33,870 & 1.1 & 98.9 & 0.30 & 0.018 \\
\hline 70 & Kapa Hi Fi & 33,870 & 2.6 & 97.4 & 0.20 & 0.015 \\
\hline 80 & Uracil+ & 33,870 & 5.8 & 94.2 & 0.13 & 0.014 \\
\hline 90 & & 33,870 & 28.4 & 71.6 & 0.12 & 0.010 \\
\hline 100 & & 33,870 & 43.9 & 56.1 & 0.12 & 0.009 \\
\hline 50 & LP-PCR-1 & 11,008 & 4.7 & 95.3 & 4.07 & 0.033 \\
\hline 60 & & 11,008 & 11.7 & 88.3 & 1.86 & 0.030 \\
\hline 70 & Taq Gold & 11,008 & 27.3 & 72.7 & 0.34 & 0.020 \\
\hline 80 & & 11,008 & 45.0 & 55.0 & 0.20 & 0.014 \\
\hline 90 & & 11,008 & 77.3 & 22.7 & $<0.01$ & 0.007 \\
\hline 100 & & 11,008 & 87.2 & 12.8 & $<0.06$ & 0.006 \\
\hline 50 & LP-PCR-2 & 23,142 & 1.4 & 98.6 & 0.91 & 0.037 \\
\hline 60 & & 23,142 & 3.3 & 96.7 & 0.62 & 0.033 \\
\hline 70 & Kapa2G & 23,142 & 10.5 & 89.5 & 0.30 & 0.024 \\
\hline 80 & Robust & 23,142 & 25.4 & 74.6 & 0.14 & 0.020 \\
\hline 90 & & 23,142 & 63.5 & 36.5 & 0.09 & 0.013 \\
\hline 100 & & 23,142 & 85.7 & 14.3 & 0.15 & 0.009 \\
\hline 50 & LP-PCR-3 & 20,252 & 4.6 & 95.4 & 6.44 & 0.016 \\
\hline 60 & & 20,252 & 13.8 & 86.2 & 2.00 & 0.015 \\
\hline 70 & Platinum & 20,252 & 23.4 & 76.6 & 0.35 & 0.013 \\
\hline 80 & Hi Fi Taq & 20,252 & 34.8 & 65.3 & 0.15 & 0.011 \\
\hline 90 & & 20,252 & 71.7 & 28.3 & $<0.04$ & 0.004 \\
\hline 100 & & 20,252 & 92.0 & 8.0 & $<0.07$ & 0.004 \\
\hline
\end{tabular}

a Consensus sequences were excluded due to failure to achieve the required majority at each level of consensus at each nucleotide position, likely due to in vitro PCR recombination

b Incorrect bases at non drug resistant sites 
and $100 \%$ majorities applied, and consensus sequences were generated from the survivors (Table 2) at each of the 10 drug resistance sites. Where a mixture was detected at any position in a specific primer ID bin at less than the stated majority, that consensus sequence was eliminated from consideration. The final data set was then analyzed for recombinants that were missed by the filtering pipeline at the ten drug resistance sites and for incorrect bases at all non-drug resistant sites. As italicized in Table 2, uSGS at the $\geq 80 \%$ supermajority achieved the most accurate data set resulting in an error rate equivalent to that of RT in vitro [25], while preserving 94.4\% of the original cDNA sequences. By contrast, the other 3 methods were able to achieve the same accuracy at the $\geq 80 \%$ supermajority cutoff but with a much greater cost to the number of final sequences, with reductions in the size of the final data set ranging from 25 to $45 \%$. Because recombination only destroys linkage of alleles, detecting linkage among drug resistance sites would be hampered in libraries generated from clinical samples using LP-PCR-1, 2 or 3 given the in vitro recombination rates observed, whereas detection of such linked alleles would be much more likely in libraries generated using uSGS.

To further illustrate this finding, neighbor-joining (NJ) trees were generated for a random selection of 50 supermajority consensus sequences produced from the mixtures sequenced using each method (Fig. 2). Also shown on the trees are the BH10 WT and mutant HIV-1 reference sequences. The orange circles represent sequences with mixtures of nucleotides at one or more of the 10 ten drug resistance sites, which failed to satisfy the supermajority requirement and therefore would be deleted from the dataset. In this random sampling, 50, 26 and $40 \%$ of the sequences would have been be omitted from the LPPCR-1, LP-PCR-2 and LP-PCR-3 datasets respectively compared to only $8 \%$ from the uSGS dataset.

\section{Calculating allele frequencies}

To compare the ability of all methods to accurately determine allele frequencies, cDNA libraries were obtained from mixtures of mutant RNA transcripts in a WT background from 10 to $1 \%$ for uSGS vs. LP-PCR-1 (Table 3a, b) and from mixtures of $30-0.3 \%$ for uSGS vs. LP-PCR-2 and LP-PCR-3 (Table 3d, e). Each cDNA mixture was divided in half for the first comparison described above and in thirds for the second. To determine whether PCR recombination results in the loss of sensitivity for detection of individual alleles, consensus sequences where built from the $>50$ and $\geq 80 \%$ supermajority of reads. Recombinants were retained for this analysis (Table 3 ). An obvious loss of mutant alleles toward the $5^{\prime}$ end of the transcripts was evident in the LP-PCR-1, 2, and 3 but not in the uSGS data (Table 3a-e). This loss of mutant alleles, most evident in the $\geq 80 \%$ majority cutoff (Table $3 \mathrm{~b}, \mathrm{e}$ ), was likely due to premature DNA polymerase (or RT) termination followed by extension of the termination product on the more abundant WT template during the early cycles of PCR in the LP-PCR-1,2,3 protocols. Consistent with this hypothesis, the allele frequencies in the raw sequence data from these methods (without generating consensus sequences) did not exhibit such bias (Table 3c) due to the fact that the individual alleles were still present regardless of whether they were in recombinant species or not.

\section{Usage of different enzymes}

To determine if the DNA polymerase used was the basis for the superior performance of uSGS compared to the other 3 methods, we conducted three parallel experiments in which uSGS or LP-PCR-1 were used to generate NGS libraries from mixtures of WT and mutant RNAs while varying the DNA polymerase used. AmpliTaq Gold (used in LP-PCR-1), Kapa Uracil + DNA polymerase (used for uSGS) and Platinum Taq (used in LP-PCR-3) were compared (Table 4). For all comparisons, the uSGS method, regardless of the enzyme used, provided a more complete sampling of the viral population, maintaining more of the starting cDNA represented in the final data set, as well as, retaining $\geq 90 \%$ of the final sequences after PCR errors and recombinants were removed (Table 4). While the Kapa Uracil +enzyme is an important component of the USGS reaction because of its ability to copy $\mathrm{dU}$-containing templates, we suggest that the use of shorter primers and efficient ligation are more important for optimizing the performance of the method. Moreover, it cannot be presumed that using a polymerase with the highest reported fidelity would reduce the error rate in any PCR method because polymerase processivity (or lack thereof), not fidelity, is the enzymatic property most likely to contribute to PCR recombination.

\section{Comparison of uSGS to LP-PCR for analysis of a clinical sample}

To compare the methods for clinical samples, NGS libraries were constructed using LP-PCR-1 and uSGS on primer ID-containing cDNA prepared from a plasma sample collected from an untreated, chronically HIV-1 infected donor. The product $(\sim 13,600$ copies of cDNA) was then divided in half for parallel library construction using LP-PCR-1 or uSGS. LPPCR and uSGS recovered 2091 and 2237 supermajority consensus sequences, respectively. Random subsets of 15 aligned supermajority sequences were selected to assess the extent of in vitro recombination (Fig. 3). 

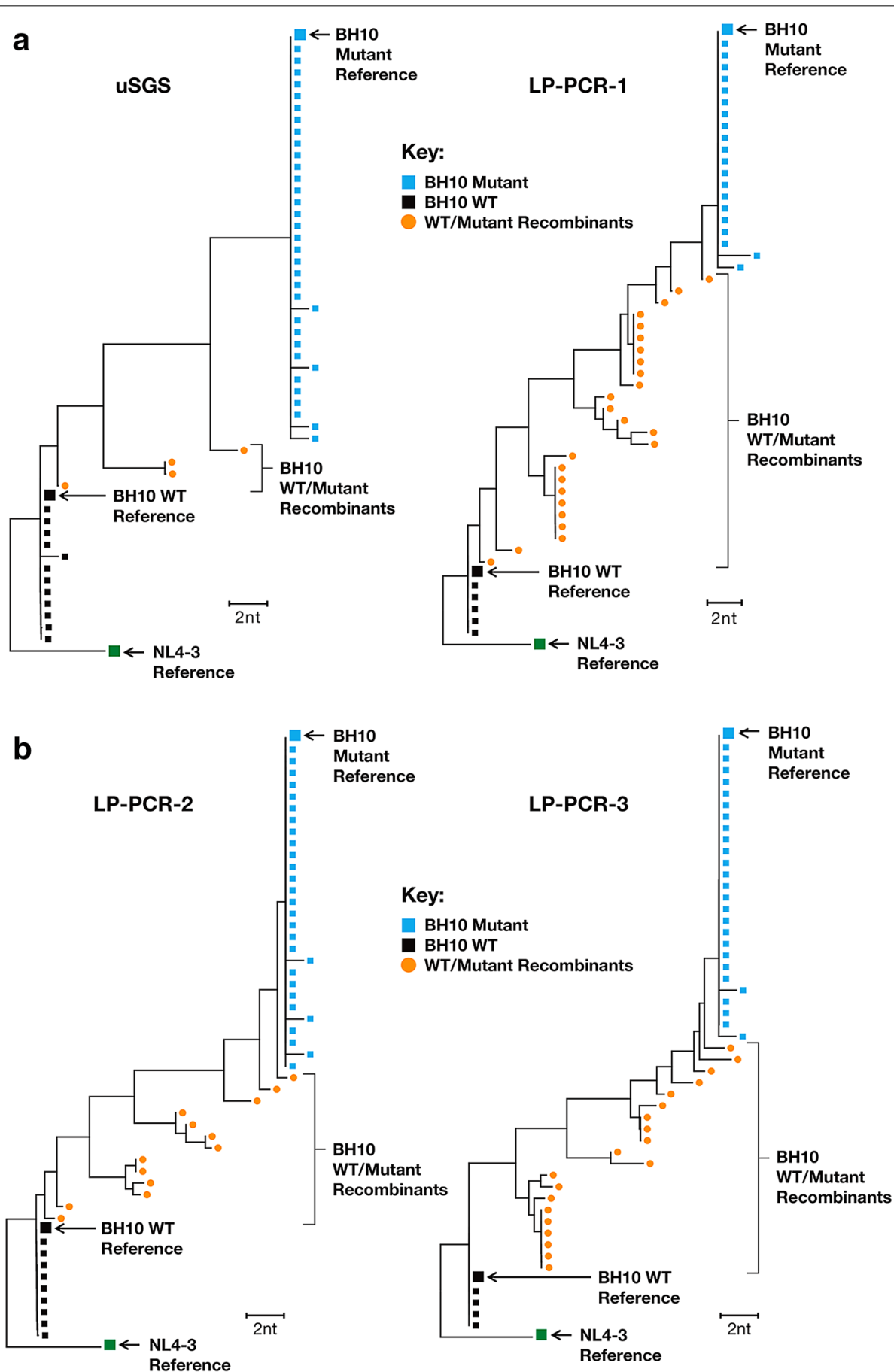

Fig. 2 Neighbor joining trees comparing PCR recombination in each method. Neighbor joining trees rooted on NL4-3 generated from randomly selected sets of 50 supermajority sequences obtained from mixtures of WT and Mutant $\mathrm{BH} 10 \mathrm{pol}$ transcripts. Reference sequences for the BH10 mutant and WT and NL4-3 WT are shown in large blue, black and green squares, respectively. Sequences matching the references are shown in the same colors as the references. The orange circles show an intermediate step in the bioinformatics computations and represent those sequences identified as PCR recombinant species that would be lost from the respective data sets after they were deleted in the final steps of the pipeline

Only 3 of the 15 supermajority sequences analyzed from the LP-PCR-1 method were found to accurately reflect their parent $\mathrm{cDNA}$, with the 12 remaining sequences containing ambiguous base calls (shown as dashes) among the 72 nt positions represented in the figure. The ambiguous sites are in areas of higher 


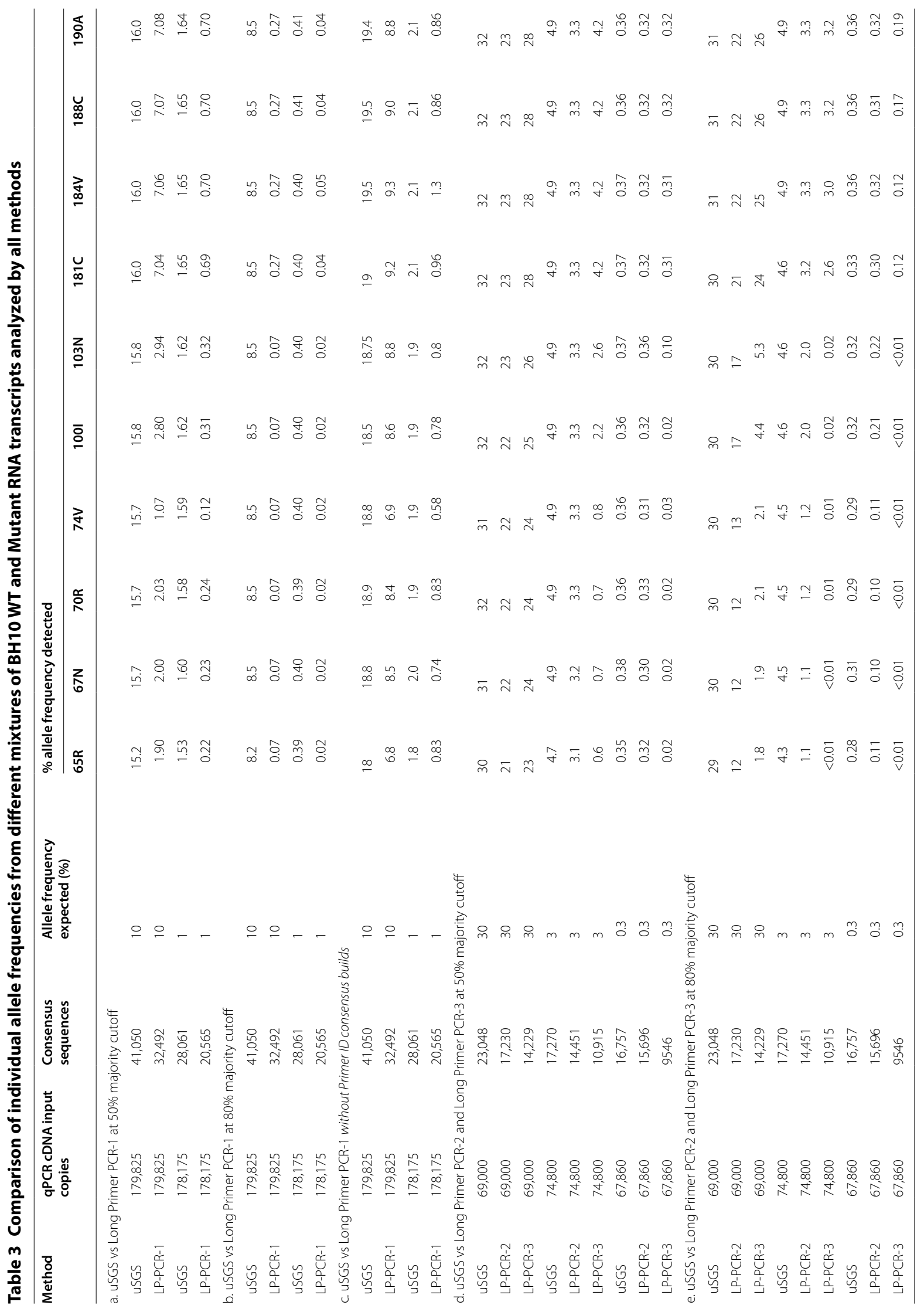


Table 4 Comparison of different DNA polymerases for library preparation using LP-PCR-1 and uSGS

\begin{tabular}{|c|c|c|c|c|c|c|}
\hline Method & Enzyme & cDNA starting copy & $\begin{array}{l}\text { Qualified } \\
\text { sequences }\end{array}$ & $\begin{array}{l}\text { \% Sequences } \\
\text { excluded }^{\text {a }}\end{array}$ & Final \# sequences & $\begin{array}{l}\% \text { Population } \\
\text { represented }\end{array}$ \\
\hline LP-PCR-1 & $\begin{array}{l}\text { AmpliTaq } \\
\text { Gold }^{b}\end{array}$ & 34,094 & 11,215 & 40 & 6729 & 20 \\
\hline USGS & $\begin{array}{l}\text { AmpliTaq } \\
\text { Gold }^{b}\end{array}$ & 34,094 & 11,859 & 7 & 11,060 & 32 \\
\hline LP-PCR-1 & $\begin{array}{l}\text { Kapa } \\
\text { Uracil+ }^{\text {b }}\end{array}$ & 34,094 & 3566 & 11 & 3188 & 9 \\
\hline USGS & $\begin{array}{l}\text { Kapa } \\
\text { Uracil+ }^{\text {b }}\end{array}$ & 34,094 & 18,855 & 2 & 18,512 & 54 \\
\hline LP-PCR-1 & $\begin{array}{l}\text { Platinum } \\
\text { Taq }^{c}\end{array}$ & 14,410 & 2789 & 82 & 558 & 4 \\
\hline USGS & $\begin{array}{l}\text { Platinum } \\
\text { Taq }^{c}\end{array}$ & 88,560 & 25,773 & 10 & 22,938 & 26 \\
\hline
\end{tabular}

\section{HIV-1 RT Codon}

62 | 63 | 64 | 65 | 66 | 67 | 68 | 69 | 70 | 71 | 72 | 73 | 74 | 75 | 76 | 73 | 73 | 78 | 79 | 80 | 81 | 82 | 83 | 83 | GCCATAA-GAAAAAGGACAGTACTAA-tGgAGAAATTAGTAGATTTCAGG-AACTTAATAA-AGAACTCAA GCCATAAG-AAAAA-GACAGTACTAA-TGGAGAAAATTAGTAGATTTCAG-GAACTTAATAAGAGAACTCAA GCCATAAAGAAAAAGGACAGTACTAAATGGAGAAAATTAGTAGATTTCAGAGAACTTAATAAAAGAACTCAA GCCATAAAGAAAAAGGACAGTACTAA-TGGAGAAA-TTAGTAGATTTCAGAGAACTTAATAAAAGAACTCAA GCCATAAGGAAAAA-GACAGTACTAA-TGGAGAAAATTAGTAGATTTCAGAGAACTTAATAA-AGAACTCAA

$\ulcorner$ GCCATAA-GAAAAAGGACAGTACTAA-TGGAGAAAATTAGTAGATTTCAGG-AACTTAATAA-AGAACTCAA

등 GCCATAAAGAAAAAGGACAGTACTAA-TGGAGAAAATTAGTAGATTTCAGAGAACTTAATAAA-GAACTCAA

GCCATAAGGAAAAAGGACAGTACTAAGTGGAGAAAATTAGTAGATTTCAGGGACTTAATAAGAGAACTCAA

GCCATAAG-AAAAA-GACAGTACTAAATGGAGAAAATTAGTAGATTTCAGAGAACTTAATAA-AGAACTCAA

GCCATAAGAAAAA--GACAGTACTAAATGGAGAAAATTAGTAGATTTCAGAGAACTTAATAAAAGAACTCAA GCCATAA-GAAAAAGGACAGTACTAAATGGAGAAA-TTAGT-GATTTCAGAGAACTTAATAA-AGAACTCAA GCCATAAG-AAAAAGGACAGTACTAA-TGGAGAAAATTAGTAGATTTCAGAGAACTTAATAA-AGAACTCAA GCCATAAGGAAAAAGGACAGTACTAAGTGGAGAAAATTAGTAGATTTCAGGGAACTTAATAAGAGAACTCAA GCCATAAGAAAAA--GACAGTACTAAATGGAGAAAATTAGTAGATTTCAGAGAACTTAATAAAAGAACTCAA GCCATAAAGAAAAGGACAGTACTAAATGGAGAAAATTAGTAGATTTCAG-GAACTTAATAAAAGAACTCAA **

GCCATAAGGAAAAAAGACAGTACTAAATGGAGAAAGTTAGTAGATTTCAGAGAACTTAATAAAAGAACTCAA GCCATAAGAAAAAAGGACAGTACTAAGTGGAGAAAATTAGTAGATTTCAGAGAACTTAATAAAAGAACTCAA GCCATAAGGAAAAAAGACAGTACTAA-TGGAGAAAATTAGTAGATTTCAGAGAACTTAATAAAAGAACTCAA GCCATAAAGAAAAAGGACAGTACTAAATGGAGAAAATTAGTAGATTTCAGAGAACTTAATAAAAGAACTCAA GCCATAAGGAAAAAAGACAGTACTAAATGGAGAAAATTAGTAGATTTCAGAGAACTTAATAAGAGAACTCAA GCCATAAAGAAAAGGACAGTACTAAATGGAGAAAATTAGTAGATTTCAGAGAACTTAATAAAAGAACTCAA

o) GCCATAAGGAAAAAGGACAGTACTAAGTGGAGAAAATTAGTAGATTTCAGGGAACTTAATAAGAGAACTCAA

O5 GCCATAAAGAAAAAGGACAGTACTAAATGGAGAAAATTAGTAGATTTCAGAGAACTTAATAAAAGAACTCAA

S) GCCATAAAGAAAAAGGACAGTACTAAATGGAGAAAATTAGTAGATTTCAGAGAACTTAATAAAAGAACTCAA GCCATAAGGAAAAAGGACAGTACTAAGTGGAGAAAATTAGTAGATTTCAGGGAACTTAATAAGAGAACTCAA GCCATAAGGAAAAAAGACAGTACTAAATGGAGAAAATTAGTAGATTTCAGAGAACTTAATAAGAGAACTCAA GCCATAAGGAAAAAGGACAGTACTAAGTGGAGAAAATTAGTAGATTTCAGGGAACTTAATAAGAGAACTCAA GCCATAAAGAAAAAGGACAGTACTAAATGGAGAAAATTAGTAGATTTCAGAGAACTTAATAAAAGAACTCAA GCCATAAGGAAAAAGGACAGTACTAAGTGGAGAAAATTAGTAGATTTCAGGGAACTTAATAAGAGAACTCAA GCCATAAAGAAAAAGGACAGTACTAAATGGAGAAAGTTAGTAGATTTCAGAGAACTTAATAAAAGAACTCAA

Fig. 3 Snapshot of sequence alignments of library construction obtained from clinical sample. Small subsets of supermajority sequence alignments obtained from a donor sample using the (a) LP-PCR or (b) USGS methods of NGS library construction. Dashes (" - " in red) which have been placed in the consensus sequences by the bioinformatics pipeline in positions with $<80 \%$ identity in sequences in a given daughter set, which is indicative of recombination during PCR. Asterisks mark positions with diverse bases in the USGS data where no PCR recombination is seen

diversity in the sequence, suggesting that the sequences were PCR recombinants. By contrast, the uSGS method produced only a single ambiguous base indicating rare PCR recombination and the suitability of this approach for analyzing linkage and population structure after identifying and omitting such recombinants. After the filtering pipeline was applied to discard consensus sequences with $>2$ ambiguous bases, uSGS preserved $96 \%$ of the original cDNA sequences whereas the LPPCR-1 dataset preserved $<40 \%$. 


\section{Application of uSGS to clinical samples}

To assess the robustness and sensitivity of the uSGS assay, we applied the assay using $1 \mathrm{ml}$ from each of 3 plasma samples with viral loads of 5000-10,000 copies/ $\mathrm{ml}$ from two HIV-infected donors on failing antiretroviral therapy. uSGS data were assessed for unique linkage among HIV-1 drug resistant variants and for population structure using neighbor-joining (NJ) trees (Table 6; Fig. 4), which allow visualization of the alignments without imposing any evolutionary assumptions on the relationships between sequences.

Of the 3470 total consensus sequences from all 3 samples, an average of $1 \%$ were lost to analysis due to $>2$ ambiguous bases from in vitro recombination, resulting in 677-1577 final sequences per sample, or $30-80$ fold more sequences than are customary for standard SGS (usually 20-50 sequences). The $\mathrm{NJ}$ tree of the sequences from donor 1 (Fig. 4) revealed clusters of resistant variants on multiple independent nodes. Within these clusters, rare HIV-1 variants (haplotypes) were detected in each sample. For example, in the sample from patient 1 (sample 1), the frequencies of RT codons $106 \mathrm{~V}$ (WT), 101Q and 108I (mutants) were approximately 9, 4 and $0.5 \%$, respectively (Table 5 ). If one assumes that these frequencies are mutually independent, the expected frequency of the haplotype containing all three alleles is $\sim 0.002 \%$ (Table 6 ). However, we found that the frequency of the $101 \mathrm{Q} / 106 \mathrm{~V} / 108 \mathrm{I}$ haplotype was $0.13 \%$ (Table 6 and expanded section of NJ tree in Fig. 4), significantly different $(\mathrm{p}=0.0004)$ from the expected frequency. In addition, 4 of the 5 haplotypes containing $106 \mathrm{~V}$ in the cluster were present at significantly higher frequencies than expected from mutual independence $\left(\mathrm{p}=<1.0 \times 10^{-237}\right.$ to 0.004 ; Table 6$)$. These results imply that the clustering of alleles observed in the neighbor joining analyses (Fig. 4) could not have arisen by chance reshuffling during PCR and therefore accurately represent the HIV-1 population in vivo.

\section{Discussion}

SGS was originally developed to circumvent errors inherent in earlier methods of analysis of the genetic structure of viral populations, including PCR induced mutation and recombination, as well as resampling of the same templates. NGS is being increasingly utilized by researchers for the same purpose, and offers significant advantages over SGS in expense and throughput. However, in its simplest form this new technology is subject to the same errors-mutation, recombination, and resampling-that SGS was designed to prevent. Great care must be taken to ensure that errors introduced by the method of library construction are minimized, and are not falsely interpreted as being characteristic of the population being analyzed. Methods (e.g. Nextera [26]) that do not permit the targeted identification of individual molecules or determination of the numbers of cDNA molecules that have been synthesized, amplified, and sequenced cannot be used to accurately reconstruct intrapatient population structure or genetic relationships of viral RNA or DNA populations. As described here and in recent studies, the use of primer IDs using different methods of library preparation and analysis to track each molecule and its amplified progeny during NGS library construction has helped to resolve this problem $[2,19,20,27]$. However, the methods used to date to generate such targeted libraries remain subject to early cycle PCR-recombination and or early cycle PCR error resulting in sequence data that may not be entirely accurate and could have the potential to miss low frequency alleles. In fact, we observed a decrease in the sensitivity of detecting some mutant alleles toward the $5^{\prime}$ end of the transcript using the LP-PCR-1, 2 and 3 methodologies. The striking $5^{\prime}$ to $3^{\prime}$ bias, likely reflects small amounts of premature termination products in the initial cDNA (i.e. truncated cDNAs). Since the same cDNA was used for all the analyses, the bias most likely arises from reduced priming efficiency of the extended primers used in the LP protocols relative to that of our short primers or the truncated cDNA sequences. In the first PCR cycle, the completed cDNA products will be copied into plus strands, which will in turn be copied initiating on to the added primer or the $3^{\prime}$ truncated cDNA. The frequency of $5^{\prime}$ biased recombination in this step will be a function of the relative priming efficiency of the two primers (truncated cDNA vs. reverse LP primer). We hypothesize that the non-complementary $5^{\prime}$ extensions (index and adaptor sequence) of the LPs greatly reduces their efficiency in the second cycle (relative to the truncated cDNAs), when only a small $3^{\prime}$ portion of the LP primer is paired with the $3^{\prime}$ end of the first cycle product, allowing recombinant products primed by the truncated cDNAs to predominate. Since the truncated cDNAs will prime randomly on the first cycle products, this effect will cause $5^{\prime}-3^{\prime}$ biased loss of minority alleles in the final PCR products. Consistent with this concept, when allele frequencies were determined using the raw sequence data, no bias was encountered because all individual alleles were counted irrespective of recombination. However, without using primer IDs, the alleles are in a background of PCR and sequencing errors and so there is no ability to distinguish background from actual genetic polymorphism or to infer the correct population structure due to resampling artifacts. These results highlight not only that detection of linkage among rare variants is hampered in LP-PCR-1, 2 or 3 methods from in vitro recombination in the early cycles of PCR, but that the USGS method can 


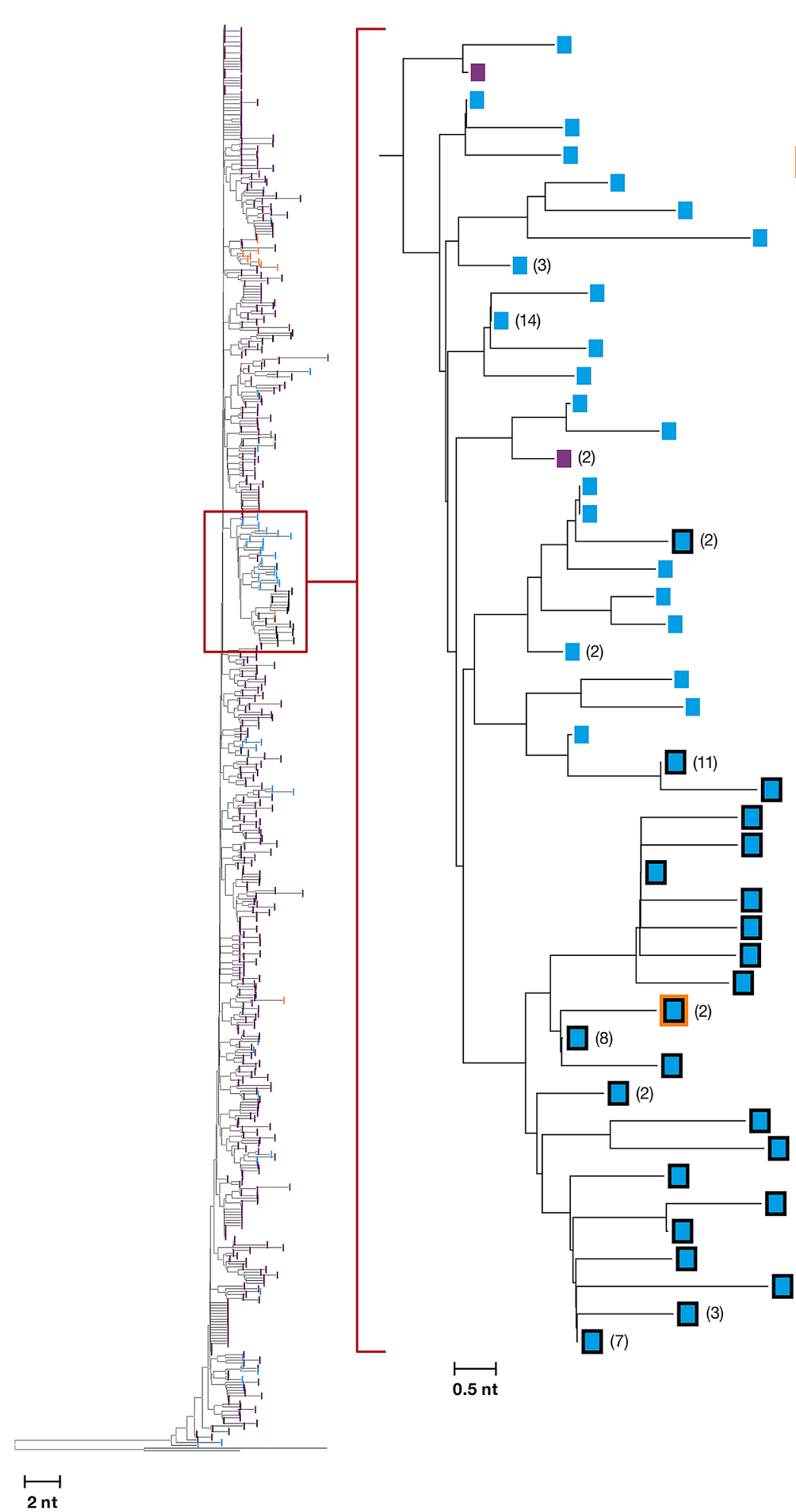

Key:

口 67N/101E/106I/190A/215Y/219R

67N/101E/V106V/190A/215Y/219R

$\square$ 67N/101Q/V106V/190A/215Y/219R

$\square$ 67N/101Q/V106V/108I/190A/215Y/219R

Note: V106V (WT)

$2 \mathrm{nt}$

Fig. 4 Analysis of HIV-1 population structure in a clinical sample using USGS for library construction. Neighbor joining trees of HIV-1 pol sequence from donor 1 sample 1 and blow up of NJ subtree, showing clustering and linkage of WT at RT position 106 (V106V blue squares) with 101Q (blue square with black outline). Numbers of identical sequences are shown in parentheses as this NJ tree was extracted from 1585 unique SGS, where identical sequences were collapsed. Within the highlighted subtree, note especially two sequences (2) in which WT RT codon 106, and rare mutations $101 \mathrm{Q}$ and $108 \mathrm{l}$ (blue square with black and orange out line) were found to be linked. Detection of such a rare linkage event would be virtually impossible using LP-PCR or conventional SGS. Data were obtained by NGS USGS and rooted on Consensus B 
Table 5 Frequency of resistance mutations in donors failing anti-retroviral therapy as measured by uSGS

\begin{tabular}{|c|c|c|c|}
\hline Allele & $\begin{array}{l}\text { Donor } 1 \text { Sample } 1 \\
\% \text { Frequency } \\
\text { (1585 uSGS) }\end{array}$ & $\begin{array}{l}\text { Donor } 1 \text { Sample } 2 \\
\% \text { Frequency } \\
\text { (675 uSGS) }\end{array}$ & $\begin{array}{l}\text { Donor } 2 \text { Sample } 3 \\
\% \text { Frequency } \\
1227 \text { (uSGS) }\end{array}$ \\
\hline D67N & 100 & 99.85 & 99.92 \\
\hline T69A & $<0.06$ & 0.15 & 0.08 \\
\hline T69| & 0.06 & $<0.15$ & $<0.08$ \\
\hline K70N & $<0.06$ & $<0.15$ & 0.08 \\
\hline K70Q & $<0.06$ & $<0.15$ & 1.07 \\
\hline К70T & $<0.06$ & $<0.15$ & 1.23 \\
\hline L74I & $<0.06$ & $<0.15$ & 0.08 \\
\hline K101E & 95.56 & 95.72 & $<0.08$ \\
\hline K101Q & 4.12 & 3.99 & 0.08 \\
\hline K101R & $<0.06$ & $<0.15$ & 0.49 \\
\hline V106l & 91.12 & 91.58 & 0.33 \\
\hline V108A & $<0.06$ & $<0.15$ & 0.08 \\
\hline V108I & 0.51 & $<0.15$ & 0.41 \\
\hline M184I & $<0.06$ & $<0.15$ & 0.16 \\
\hline M184V & $<0.06$ & $<0.15$ & 99.84 \\
\hline Y188C & 0.06 & $<0.15$ & $<0.08$ \\
\hline G190A & 99.81 & 100 & $<0.08$ \\
\hline G190E & $<0.06$ & $<0.15$ & 0.08 \\
\hline G190R & $<0.06$ & $<0.15$ & 0.08 \\
\hline G190T & 0.13 & $<0.15$ & $<0.08$ \\
\hline $\mathrm{T} 215 \mathrm{~F}$ & 0.06 & $<0.15$ & $<0.08$ \\
\hline T215R & $<0.06$ & $<0.15$ & $<0.08$ \\
\hline T215Y & 99.94 & 100 & 100 \\
\hline K219R & 99.94 & 99.85 & $<0.08$ \\
\hline
\end{tabular}

correct this deficiency. For this reason, we developed a method of library preparation for targeted NGS of HIV-1 RNA, which results in very low early cycle PCR-recombination and more complete sampling of cDNA libraries. Combined with a more stringent bioinformatics pipeline for filtering out early PCR errors, this approach results in datasets that are virtually free of PCR error and PCR recombination. Consequently, our uSGS methodology is the most effective means for studying HIV-1 population structure as well as for detecting linkage among rare alleles. Critical features of this methodology include (1) amplification of primer ID-tagged cDNA molecules using short primers and a more robust DNA polymerase that catalyzes PCR uniformly and efficiently [28] and (2) creation of 17 base $3^{\prime}$ overhangs at both ends of the amplicons to promote highly efficient ligation of linkers containing NGS adaptors [22, 23], which eliminates the need for a subsequent PCR amplification step. Other protocols requiring that NGS adapters be attached to dsDNA libraries by blunt-end or nearly blunt-end ligation, (i.e., via single nucleotide $3^{\prime}$ overhangs) or in vitro transposition $\left(\right.$ Nextera $\left.{ }^{\circledR}\right)$ are relatively inefficient [29]. Only small fractions of amplicons are successfully appended in these reactions, necessitating subsequent rounds of PCR prior to sequencing $[3,29]$, likely resulting in amplification bias.

As previously reported, mutation arising in primer IDs during PCR amplification have the potential to generate artifacts during NGS library production [15-19]. To address this issue, we have also included in our analysis pipeline methods developed by Zhou et al. [19] that identify and exclude such false primer IDs. These tools allow us to employ primer IDs without being misled by artifacts produced during library amplification.

In conclusion, the uSGS method for targeted, massively parallel sequencing of HIV-1 RNA-derived cDNA libraries (1) results in a higher fraction of cDNAs being amplified and sequenced and (2) virtually eliminates in vitro recombination and PCR error, resulting in hundreds to thousands of single-genome HIV-1 sequences that accurately reflect the population genetics of the parent RNA. This method can also be used to determine linkage of low frequency HIV-1 drug resistance mutations and can be modified to assess RNA populations of other viruses or expressed host genes.

\section{Methods \\ RNA preparation and CDNA synthesis}

Mixtures of WT and multidrug resistant mutant HIV-1 BH10 pol RNA transcripts were derived from cloned viral DNA as previously described by Shao et al. [2]. An 895bp region of HIV-1 BH10 WT and mutant transcripts containing codons 22-291 in HIV-1 pol was used for controls. Mixtures of WT and multidrug resistant transcripts containing 10 well characterized drug resistance mutations, distributed along the 546nt fragment, were used for analyzing in vitro recombination. Viral RNA from donor plasma was extracted as described previously and placed on ice [30]. RNAs were reverse transcribed in $50 \mu \mathrm{L}$ reactions that included $30 \mathrm{nM}$ final concentration of HIV-1 gene specific primer with Primer ID (GSPID 2834R), $500 \mu \mathrm{M}$ dNTPs (Promega C1145), $1 \times$ First Strand Buffer, $1 \mathrm{~mm}$ DTT, $20 \mathrm{U}$ RNase out (Promega Cat \#N2115; $40 \mathrm{U} / \mu \mathrm{l}$ ) and $200 \mathrm{U}$ SuperScript III (Life Technologies, Cat \#18080-044; $200 \mathrm{U} / \mu \mathrm{l})$. Oligonucleotide sequences are provided in the "Appendix".

Reverse transcription reactions were incubated at $45{ }^{\circ} \mathrm{C}$ for $1 \mathrm{~h}$ and quenched to $4{ }^{\circ} \mathrm{C}$. 60 units of Exonuclease 1 (NEB: Cat \#M0293S), and 1U Shrimp Alkaline Phosphatase (NEB: Cat \#M0371S) were added and incubated as follows: $37{ }^{\circ} \mathrm{C}$ for $30 \mathrm{~min}$ and $85^{\circ} \mathrm{C}$ for $15 \mathrm{~min}$. 5 units of RNase H (NEB: Cat \#M0297S) were added 
Table 6 Linkage of resistance mutations in donors failing anti-retroviral therapy as measured by uSGS

\begin{tabular}{|c|c|c|c|c|}
\hline Patient/sample & $\begin{array}{l}\text { Haplotypes } \\
\text { Mutant codons in italics }\end{array}$ & Expected (\%) & Observed (\%) & P value \\
\hline \multirow[t]{15}{*}{$1 / 1$} & $67 \mathrm{~N}, 69 \mathrm{~T}, 101 \mathrm{E}, 106 \mathrm{I}, 108 \mathrm{~V}, 188 \mathrm{Y}, 190 \mathrm{~A}, 215 \mathrm{~F}, 219 \mathrm{R}$ & 0.05 & 0.06 & 0.58 \\
\hline & $67 \mathrm{~N}, 69 \mathrm{~T}, 101 \mathrm{Q}, 106 \mathrm{~V}, 108 \mathrm{I}, 188 \mathrm{Y}, 190 \mathrm{~A}, 215 \mathrm{Y}, 219 \mathrm{R}$ & 0.002 & 0.13 & 0.0004 \\
\hline & $67 \mathrm{~N}, 69 \mathrm{~T}, 101 \mathrm{E}, 106 \mathrm{~V}, 108 \mathrm{~V}, 188 \mathrm{Y}, 190 \mathrm{~A}, 215 \mathrm{Y}, 219 \mathrm{R}$ & 8.41 & 5.58 & $1.18^{*} 10^{-5}$ \\
\hline & $67 \mathrm{~N}, 69 \mathrm{~T}, 101 \mathrm{E}, 106 \mathrm{~V}, 108 \mathrm{l}, 188 \mathrm{Y}, 190 \mathrm{~A}, 215 \mathrm{Y}, 219 \mathrm{R}$ & 0.04 & 0.06 & 0.49 \\
\hline & $67 \mathrm{~N}, 69 \mathrm{~T}, 101 \mathrm{Q}, 106 \mathrm{~V}, 108 \mathrm{~V}, 188 \mathrm{Y}, 190 \mathrm{~A}, 215 \mathrm{Y}, 219 \mathrm{R}$ & 0.36 & 3.04 & $1.0^{*} 10^{-237}$ \\
\hline & $67 N, 69 \mathrm{~T}, 101 \mathrm{Q}, 106 \mathrm{~V}, 108 \mathrm{~V}, 188 \mathrm{Y}, 190 \mathrm{G}, 215 \mathrm{Y}, 219 R$ & 0.0002 & 0.06 & 0.004 \\
\hline & $67 N, 69 \mathrm{~T}, 101 \mathrm{E}, 106 \mathrm{I}, 108 \mathrm{I}, 188 \mathrm{Y}, 190 \mathrm{~A}, 215 \mathrm{Y}, 219 \mathrm{R}$ & 0.44 & 0.25 & 0.18 \\
\hline & $67 \mathrm{~N}, 69 \mathrm{~T}, 101 \mathrm{E}, 1061,108 \mathrm{~V}, 188 \mathrm{Y}, 190 \mathrm{~T}, 215 \mathrm{Y}, 219 \mathrm{R}$ & 0.11 & 0.13 & 0.52 \\
\hline & $67 \mathrm{~N}, 69 \mathrm{~T}, 101 \mathrm{E}, 106 \mathrm{I}, 108 \mathrm{~V}, 188 \mathrm{Y}, 190 \mathrm{~A}, 215 \mathrm{Y}, 219 \mathrm{R}$ & 86.25 & 89.22 & 0.0003 \\
\hline & $67 \mathrm{~N}, 69 \mathrm{~T}, 101 \mathrm{E}, 106 \mathrm{I}, 108 \mathrm{~V}, 188 \mathrm{Y}, 190 \mathrm{~A}, 215 \mathrm{Y}, 219 \mathrm{~K}$ & 0.05 & 0.06 & 0.58 \\
\hline & $67 \mathrm{~N}, 69 \mathrm{~T}, 101 \mathrm{~K}, 106 \mathrm{I}, 108 \mathrm{~V}, 188 \mathrm{Y}, 190 \mathrm{~A}, 215 \mathrm{Y}, 219 \mathrm{R}$ & 0.34 & 0.38 & 0.46 \\
\hline & $67 \mathrm{~N}, 69 \mathrm{~T}, 101 \mathrm{Q}, 106 \mathrm{I}, 108 \mathrm{~V}, 188 \mathrm{Y}, 190 \mathrm{~A}, 215 \mathrm{Y}, 219 \mathrm{R}$ & 3.72 & 0.82 & $3.1 * 10^{-13}$ \\
\hline & $67 \mathrm{~N}, 691,101 \mathrm{E}, 106 \mathrm{I}, 108 \mathrm{~V}, 188 \mathrm{Y}, 190 \mathrm{~A}, 215 \mathrm{Y}, 219 \mathrm{R}$ & 0.05 & 0.06 & 0.58 \\
\hline & $67 \mathrm{~N}, 69 \mathrm{~T}, 101 \mathrm{E}, 106 \mathrm{I}, 108 \mathrm{~V}, 188 \mathrm{C}, 190 \mathrm{~A}, 215 \mathrm{Y}, 219 \mathrm{R}$ & 0.05 & 0.06 & 0.58 \\
\hline & $67 \mathrm{~N}, 69 \mathrm{~T}, 101 \mathrm{Q}, 106 \mathrm{I}, 1081,188 \mathrm{Y}, 190 \mathrm{~A}, 215 \mathrm{Y}, 219 \mathrm{R}$ & 0.02 & 0.06 & 0.26 \\
\hline \multirow[t]{9}{*}{$1 / 2$} & $67 \mathrm{~N}, 69 \mathrm{~T}, 101 \mathrm{E}, 106 \mathrm{I}, 190 \mathrm{~A}, 215 \mathrm{Y}, 219 \mathrm{~K}$ & 0.13 & 0.15 & 0.58 \\
\hline & $67 \mathrm{~N}, 69 \mathrm{~T}, 101 \mathrm{~K}, 106 \mathrm{~V}, 190 \mathrm{~A}, 215 \mathrm{Y}, 219 \mathrm{R}$ & 0.02 & 0.15 & 0.15 \\
\hline & 67D, 69T, 101E, 106V, 190A, 215Y, 219R & 0.01 & 0.15 & 0.08 \\
\hline & $67 \mathrm{~N}, 69 \mathrm{~T}, 101 \mathrm{E}, 106 \mathrm{I}, 190 \mathrm{~A}, 215 \mathrm{Y}, 219 \mathrm{R}$ & 87.42 & 90.25 & 0.01 \\
\hline & $67 \mathrm{~N}, 69 \mathrm{~T}, 101 \mathrm{Q}, 106 \mathrm{~V}, 190 \mathrm{~A}, 215 \mathrm{Y}, 219 \mathrm{R}$ & 0.33 & 3.10 & $5.1^{*} 10^{-14}$ \\
\hline & $67 \mathrm{~N}, 69 \mathrm{~T}, 101 \mathrm{~K}, 106 \mathrm{I}, 190 \mathrm{~A}, 215 \mathrm{Y}, 219 \mathrm{R}$ & 0.27 & 0.15 & 0.45 \\
\hline & $67 \mathrm{~N}, 69 \mathrm{~T}, 101 \mathrm{E}, 106 \mathrm{~V}, 190 \mathrm{~A}, 215 \mathrm{Y}, 219 \mathrm{R}$ & 8.04 & 5.02 & 0.001 \\
\hline & $67 \mathrm{~N}, 69 \mathrm{~A}, 101 \mathrm{E}, 1061,190 \mathrm{~A}, 215 \mathrm{Y}, 219 \mathrm{R}$ & 0.13 & 0.15 & 0.58 \\
\hline & $67 \mathrm{~N}, 69 \mathrm{~T}, 101 \mathrm{Q}, 106 \mathrm{I}, 190 \mathrm{~A}, 215 \mathrm{Y}, 219 \mathrm{R}$ & 3.64 & 0.89 & $6.1^{*} 10^{-6}$ \\
\hline \multirow[t]{15}{*}{$2 / 3$} & $67 \mathrm{~N}, 69 \mathrm{~T}, 70 \mathrm{Q}, 74 \mathrm{~L}, 101 \mathrm{~K}, 106 \mathrm{~V}, 108 \mathrm{~V}, 184 \mathrm{~V}, 190 \mathrm{G}, 215 \mathrm{Y}$ & 1.05 & 1.07 & 0.51 \\
\hline & $67 \mathrm{~N}, 69 \mathrm{~T}, 70 \mathrm{~K}, 74 \mathrm{~L}, 101 \mathrm{R}, 106 \mathrm{~V}, 108 \mathrm{~V}, 184 \mathrm{~V}, 190 \mathrm{G}, 215 \mathrm{Y}$ & 0.48 & 0.49 & 0.52 \\
\hline & $67 \mathrm{~N}, 69 \mathrm{~T}, 70 \mathrm{~K}, 74 \mathrm{~L}, 101 \mathrm{~K}, 106 \mathrm{~V}, 108 \mathrm{~V}, 184 \mathrm{I}, 190 \mathrm{G}, 215 \mathrm{Y}$ & 0.16 & 0.16 & 0.57 \\
\hline & 67D, 69T, 70K, 74L, 101K, 106V, 108V, 184V, 190G, 215Y & 0.08 & 0.08 & 0.62 \\
\hline & 67N.69T, 70K, 74L, 101K, 106I, 108V, 184V, 190G, 215Y & 0.32 & 0.33 & 0.54 \\
\hline & $67 \mathrm{~N}, 69 \mathrm{~T}, 70 \mathrm{~K}, 74 \mathrm{~L}, 101 \mathrm{~K}, 106 \mathrm{~V}, 108 \mathrm{~V}, 184 \mathrm{~V}, 190 \mathrm{E}, 215 \mathrm{Y}$ & 0.08 & 0.08 & 0.62 \\
\hline & 67N 69T, 70K, 74L, 101K, 106V, 108V, 184V, 190R, 215Y & 0.08 & 0.08 & 0.62 \\
\hline & $67 \mathrm{~N}, 69 \mathrm{~T}, 70 \mathrm{~K}, 74 \mathrm{I}, 101 \mathrm{~K}, 106 \mathrm{~V}, 108 \mathrm{~V}, 184 \mathrm{~V}, 190 \mathrm{G}, 215 \mathrm{Y}$ & 0.08 & 0.08 & 0.62 \\
\hline & $67 N 69 A, 70 \mathrm{~K}, 74 \mathrm{~L}, 101 \mathrm{~K}, 106 \mathrm{~V}, 108 \mathrm{~V}, 184 \mathrm{~V}, 190 \mathrm{G}, 215 \mathrm{Y}$ & 0.08 & 0.08 & 0.62 \\
\hline & $67 \mathrm{~N}, 69 \mathrm{~T}, 70 \mathrm{~N}, 74 \mathrm{~L}, 101 \mathrm{~K}, 106 \mathrm{~V}, 108 \mathrm{~V}, 184 \mathrm{~V}, 190 \mathrm{G}, 215 \mathrm{Y}$ & 0.08 & 0.08 & 0.63 \\
\hline & 67N 69T, 70T, 74L, 101K, 106V, 108V, 184V, 190G, 215Y & 1.21 & 1.23 & 0.51 \\
\hline & $67 \mathrm{~N}, 69 \mathrm{~T}, 70 \mathrm{~K}, 74 \mathrm{~L}, 101 \mathrm{Q}, 106 \mathrm{~V}, 108 \mathrm{~V} 184 \mathrm{~V}, 190 \mathrm{G}, 215 \mathrm{Y}$ & 0.08 & 0.08 & 0.62 \\
\hline & 67N 69T, 70K, 74L101K, 106V, 108V, 184V, 190G, 215Y & 95.76 & 95.64 & 0.44 \\
\hline & $67 \mathrm{~N} 69 \mathrm{~T}, 70 \mathrm{~K}, 74 \mathrm{~L}, 101 \mathrm{~K}, 106 \mathrm{~V}, 108 \mathrm{~A}, 184 \mathrm{~V}, 190 \mathrm{G}, 215 \mathrm{Y}$ & 0.08 & 0.08 & 0.62 \\
\hline & $67 \mathrm{~N}, 69 \mathrm{~T}, 70 \mathrm{~K}, 74 \mathrm{~L}, 101 \mathrm{~K}, 106 \mathrm{~V}, 108 \mathrm{I}, 184 \mathrm{~V}, 190 \mathrm{G}, 215 \mathrm{Y}$ & 0.40 & 0.41 & 0.53 \\
\hline
\end{tabular}

and incubated for $20 \mathrm{~min}$ at 37 and $85{ }^{\circ} \mathrm{C}$ for $15 \mathrm{~min}$. The cDNA was precipitated overnight at $-20{ }^{\circ} \mathrm{C}$ with 0.1 volume (v) $3 \mathrm{M}$ Sodum Acetate, $\mathrm{pH} 5.5,20 \mu \mathrm{g}$ glycogen (Roche: Cat \#1090139300) and 3v 95\% ETOH. The washed and dried precipitated cDNA was suspended in $5 \mathrm{mM}$ Tris- $\mathrm{HCl}, \mathrm{pH} 8.0$ and processed reserving $5 \mu \mathrm{l}$ for quantification by qPCR.

\section{CDNA amplification in uSGS}

Five replicate $25 \mu \mathrm{l}$ PCR reactions were performed for the first round of PCR with final concentrations as follows: $1 \times$ Kapa Hi Fi Hot Start Uracil + reaction mix (KAPABIOSYTEMS Cat \#KK2802), $300 \mathrm{nM}$ forward primer \#28F (2195), $300 \mathrm{nM}$ dU-containing reverse primer PrimRegion-R-5Us and cycled as follows: 1 cycle $95^{\circ} \mathrm{C}$ for $3 \mathrm{~min}$, 
10 cycles $95{ }^{\circ} \mathrm{C}$ for $20 \mathrm{~s}, 60^{\circ} \mathrm{C}$ for $30 \mathrm{~s}, 68$ for 2 min with $5 \mathrm{~s}$ added onto each subsequent cycle. The products from all 5 reactions belonging to the same sample were combined and purified using the Mini Elute PCR purification kit from Qiagen (Cat \#28004). A second round of PCR was performed exactly as the first except the entire purified product from the first PCR was used as template in 5 replicate reactions with final concentrations of $300 \mathrm{nM}$ primers of forward primer 2286-F-dUs and reverse primer PrimRegion-R-5Us and cycled 20-30 times. The products from all 5 reactions belonging to the same sample are combined and PCR purified using the QIAquick PCR Purification Kit from Qiagen (Cat \#28104).

\section{Processing of DNA termini and adapter ligation in uSGS}

In $50 \mu \mathrm{l}$ reactions, PCR products generated using dUcontaining primers were treated with 10 units of uracilDNA glycosylase (UDG) (NEB M0280S) and incubated for $2 \mathrm{~h}$ at $37{ }^{\circ} \mathrm{C}$. This enzyme hydrolyzes the glycosidic bonds in 2'-deoxyuridines, thereby releasing the uracil bases and generating chemically labile abasic sites at the affected positions. The UDG-treated DNA was cleaved at these abasic sites with $2 \mathrm{~N} \mathrm{NaOH}$ at a final concentration of $0.25 \mathrm{~N}$ and incubated at $65{ }^{\circ} \mathrm{C}$ for $30 \mathrm{~min}$. Solutions were neutralized by adding an equimolar amount of $2 \mathrm{M}$ Trizma Hydrochloride. DNAs were renatured by heating to $85^{\circ} \mathrm{C}$ for $2 \mathrm{~min}$, and slow cooled at $0.1{ }^{\circ} \mathrm{C} / \mathrm{s}$ to $25{ }^{\circ} \mathrm{C}$. The dsDNA was precipitated overnight at $-20{ }^{\circ} \mathrm{C}$ with $0.1 \mathrm{v} 3 \mathrm{M}$ Sodium Acetate, $\mathrm{pH} 5.5,20 \mu \mathrm{g}$ glycogen and 3v 95\% ETOH. Collectively, these treatments generated a double-stranded DNA library in which amplicons contained distinct $17 \mathrm{nt} 3^{\prime}$ overhangs at both ends. These sticky ends were complementary to the NGS adapters (Linker F1 and Linker R2), facilitating their attachment to the hydrolyzed DNA strands by bridging ligation - a process much more efficient than blunt end ligation or ligation utilizing a single nucleotide overhang, avoiding inefficient ligation and the necessity for additional cycles of PCR.

The method was completed by hybridizing NGS linkers to the 17-nt $3^{\prime}$ overhangs using $\sim 2$ pmol DNA, $1 \times$ NEB buffer \#2, 4 pmol linker F, 4 pmol linker $\mathrm{R}$ and $1 \mathrm{mM}$ final concentration of ATP (NEB Cat \#P0756S). The reactions were heated to $65^{\circ} \mathrm{C}$ for $5 \mathrm{~min}$ and slow cooled at $0.1{ }^{\circ} \mathrm{C} / \mathrm{s}$ to $25^{\circ} \mathrm{C} .400$ units of T4 DNA ligase (NEB Cat \#M0202S) was added and incubated at $25^{\circ} \mathrm{C}$ for $16 \mathrm{~h}$ (overnight), and then heated to $65^{\circ} \mathrm{C}$ for $10 \mathrm{~min}$. The $5^{\prime}$ overhangs were filled in with 5 units of Klenow Fragment DNA polymerase (NEB Cat \#M0212S) and $400 \mu \mathrm{M}$ dNTPs and incubated at $37^{\circ} \mathrm{C}$ for $2 \mathrm{~h}$.

Ligation reactions were resolved on a $1.5 \%$ agarose gel and the $\sim 719 \mathrm{bp}$ fragment was excised and purified using Qiagen Qiaquick Gel Extraction kit Cat \#28704.
Each sample was quantified using the KAPA SYBR FAST universal qPCR kit (KK4824 KAPA Biosystems) by following manufacturer's directions. Samples were normalized to $2 \mathrm{nM}$ combined and loaded for paired-end sequencing using the Illumina Miseq.

\section{CDNA amplification in LP-PCR-1}

Five replicate $25 \mu \mathrm{l}$ PCR reactions were performed for LP-PCR-1 with final concentrations of $1 \times$ SYBR green buffer, $4 \mathrm{mM} \mathrm{MgCl}_{2}, 500 \mu \mathrm{M}$ dNTPs, $5 \mathrm{U}$ AmpliTaq Gold and $300 \mathrm{nM}$ each MiSeq forward primer I and MiSeq reverse primer 2. All reactions were performed using the following cycling conditions: 1 cycle $95{ }^{\circ} \mathrm{C}$ for $10 \mathrm{~min}, 10$ cycles $95{ }^{\circ} \mathrm{C}$ for $30 \mathrm{~s}, 53{ }^{\circ} \mathrm{C}$ for $30 \mathrm{~s}, 72$ for $2 \mathrm{~min}$, then 45 cycles of $95{ }^{\circ} \mathrm{C}$ for $30 \mathrm{~s}, 72{ }^{\circ} \mathrm{C} 2 \mathrm{~min}$. Following PCR, the 5 reactions were combined and gel purified using a Qiaquick gel extraction kit as per manufacturer's protocol. Samples were quantified following manufacturer's protocol using a Kapa Library Quantification kit.

\section{CDNA amplification in LP-PCR-2}

This protocol was adapted from Zhou et al. [19] and was essentially 2 rounds of 25 cycle flanking PCR using oligos of 50 and $54 \mathrm{nt}$ in length for the first round and 58 and $61 \mathrm{nt}$ for the flanking round 2. In short, 5 replicate $25 \mu \mathrm{l}$ PCR reactions were performed for LP-PCR-2, round 1 with final concentrations of $1 \times$ Robust KapaG2 mix (Kapa Biosystems) and $200 \mathrm{nM}$ forward primer B2F and reverse B6R and cycled as follows: 1 cycle of $95^{\circ}$ $1 \mathrm{~min}, 25$ cycles of $95^{\circ} \mathrm{C} 15 \mathrm{~s}, 58^{\circ} \mathrm{C} 1 \mathrm{~min}$ and $72{ }^{\circ} \mathrm{C} 30 \mathrm{~s}$ and 1 cycle of $72{ }^{\circ} \mathrm{C}$ for $3 \mathrm{~min}$. PCR products were PCR purified using the QIAquick PCR Purification Kit from Qiagen and $2 \mu \mathrm{l}$ (of the $50 \mu \mathrm{l}$ eluted) used as template in a second round of PCR. Round 2 was performed exactly as round 1 except forward primer B6F and reverse B7R were used. All reactions were performed using the same cycling conditions as in round 1.

\section{CDNA amplification in LP-PCR-3}

This protocol was adapted from Seifert et al. [20] and comprised 3 rounds of PCR. The first round used short oligos of 25-31 nt in length in 30 cycles of PCR, the second used 30 cycles of flanking PCR using oligos of 50 and $54 \mathrm{nt}$ long and the third used 12 cycles of flanking PCR using oligos of 58 and $61 \mathrm{nt}$ in length. In short, 5 replicate $25 \mu \mathrm{l}$ PCR reactions were performed for LPPCR-3 round 1 with final concentrations of $1 \times$ Platinum taq buffer, $400 \mu \mathrm{M}$ dNTPs, $2 \mathrm{mM} \mathrm{MgSO} 4$, and $200 \mathrm{nM}$ forward primer \#28F (2195), $200 \mathrm{nM}$ reverse primer PrimRegion- $\mathrm{R}$ (the same primers used in uSGS round 1) and cycled as follows: $95{ }^{\circ} \mathrm{C} 2 \mathrm{~min}, 30$ cycles at $95^{\circ} \mathrm{C}$ $15 \mathrm{~s}, 53{ }^{\circ} \mathrm{C} 30 \mathrm{~s}, 68^{\circ} \mathrm{C} 1 \mathrm{~min}$. PCR products were diluted 
to 100,000 copies (as measured by qPCR) and used as template in a semi nested PCR round 2. Round 2 was performed exactly as round 1 except forward primer $\mathrm{B} 1 \mathrm{~F}$ and reverse B4R were used. A third round of PCR was performed following purification of the products and $1 \mathrm{ng}$ used as template in 12 additional cycles of PCR using forward primer B6F and reverse B7R and JumpStart Taq ready mix (Sigma-Aldrich P2893) and cycled as follows: $95{ }^{\circ} \mathrm{C} 2 \mathrm{~min}, 12$ cycles of $95{ }^{\circ} \mathrm{C} 30 \mathrm{~s}, 53{ }^{\circ} \mathrm{C}$ $30 \mathrm{~s}, 72{ }^{\circ} \mathrm{C} 1 \mathrm{~min}$. The 5 reactions were combined and gel purified using a Qiaquick gel extraction kit as per manufacture's protocol. Samples were quantified following manufacture's protocol using Kapa Library Quantification kit.

\section{MiSeq sequencing and analyses}

Samples were prepared for Miseq Illumina sequencing as directed in the protocol for the 500-cycle MiSeq v2 kit (MS-102-2003 Illumina Inc, San Diego, CA). A final concentration of $\sim 10 \mathrm{pM}$ of the pooled sample was spiked with $20 \%$ of the PhiX DNA control. After the Miseq runs were complete, Fastq files were exported for bioinformatics analyses. The MiSeq paired-end reads were concatenated (the reverse complement sequence was used for read 2). Low quality reads were removed using a program available at http://hannonlab.cshl.edu/fastx_toolkit (with parameters -Q20 - P90, and default for all other settings). The filtered fastq sequences were then converted to fasta format and the fasta reads were sorted by barcodes using programs available on the same website. The reads were then compared to a reference sequence and the primer IDs were determined using an in-house Perl script. Primer IDs containing indels were discarded. Reads with identical primer IDs were grouped for consensus or super-majority ( $\geq 80 \%$ identity at each site) construction. The minimum number of raw sequences for consensus construction was determined by the Zhou et al. [19] cutoff model. All primer ID groups smaller than this cutoff were discarded. For the purpose of comparing the methods presented in this manuscript, super-majority sequences containing ambiguous bases were retained. However, for analysis of clinical samples, the presence of more than one such base resulted in exclusion of that sequence from the dataset, essentially omitting the in vitro PCR recombinants from the final data. An in-house Perl script was used to determine the allele frequencies at each position. Neighbor-joining trees were constructed using Mega 6 [31]. Probabilities for the expected vs. observed haplotypes were determined with Hardy-Weinberg statistics. Miseq data will be made available in GenBank. Perl scripts used in the above analyses are available at the GitHub code repository at https://github.com/ShaoFred/MiSeq_consensus_builder.git.

\section{Authors' contributions}

VFB developed the methods, conducted experiments, analyzed the results and drafted the manuscript. JR developed the methods, conducted experiments and drafted the manuscript. WS wrote and conducted the bioinformatics for our analysis pipeline. JH conducted experiments. BL performed the statistical analyses. FM provided intellectual input and provided the patient clinical samples. JWM provided intellectual input and drafted the manuscript. MFK conceived the ideas and drafted the manuscript. JMC conceived the ideas and drafted the manuscript. All authors read and approved the final manuscript.

\section{Author details \\ ${ }^{1}$ HIV Dynamics and Replication Program, CCR, National Cancer Institute, NIH, Translational Research Unit, 105 Boyles Street, Building 535 Room 111, Freder- ick, MD 21702-1201, USA. ${ }^{2}$ Frederick National Laboratory for Cancer Research, Advanced Biomedical Computing Center, Leidos Biomedical Research, Inc, Frederick, MD, USA. ${ }^{3}$ Division of Infectious Disease, University of Pittsburgh, Pittsburgh, PA, USA. ${ }^{4}$ Department of Molecular Biology and Microbiology, Tufts University, Boston, MA, USA.}

\section{Acknowledgements}

We thank Ann Wiegand and Jon Spindler for helpful discussions and Sue Toms, Connie Kinna, and Valerie Turnquist for administrative support. We thank Paul Boyer for providing valuable reagents and Allan Kane and Joe Meyer for help with the figures. The content of this publication does not necessarily reflect the views or policies of the Department of Health and Human Services, nor does mention of trade names, commercial products, or organizations imply endorsement by the U.S. Government.

\section{Competing interests}

Valerie F. Boltz, Jason Rausch, Wei Shao, Junko Hattori, Brian Luke, Frank Maldarelli, Mary F. Kearney and John M. Coffin declare no competing financial interests. John W. Mellors discloses that he is a consultant to Gilead Sciences and owns shares in Co-Crystal, Inc. (Neither of these activities has relevance to the current manuscript). In addition, all authors declare no competing nonfinancial interests.

\section{Ethics approval and consent to participate}

Plasma samples from HIV-1 infected donors were obtained from individuals attending the National Institute of Allergy and Infectious Diseases (NIAID) Critical Care Medical Department of National Institutes of Health (NIH), Bethesda, MD. Protocol 00-I-0110 and studies were approved by the institutional review board of NIAID, NIH, Bethesda, MD. All individuals provided written informed consent.

\section{Funding}

Funding for this research was also provided by the National Cancer Institute's Intramural Center for Cancer Research, which supports the HIV Dynamics and Replication Program, and Bench to Bedside grant B11-A-14 Kearney (PI). J.M.C. was a research professor of the American Cancer Society. J.W.M receives support from Leidos Biomedical Research, Inc. contract 12XS547 through the National Cancer Institute.

\section{Appendix}

Reverse transcription primer all methods

GSPID-2834-R:

5' GGTATCGAAGTCATCCTGCTAGNNNNNNNNN NTGGAGTTCATAACCCATCCAAAG $3^{\prime}$

\section{uSGS primers and linkers}

PCR:
28-2195F
$5^{\prime}$ AAACAATGGCCATTGACAGAAG A $3^{\prime}$
2286-F-dUs $\quad 5^{\prime}$ CdUGAAAAdUCCAdUACAAdUAC TCCAGTATTTGC $3^{\prime}$ 
11. Kearney MF, Spindler J, Shao W, Yu S, Anderson EM, O'Shea A, Rehm C, Poethke C, Kovacs N, Mellors JW, et al. Lack of detectable HIV-1 molecular evolution during suppressive antiretroviral therapy. PLoS Pathog. 2014;10:e1004010.

12. Bailey JR, Sedaghat AR, Kieffer T, Brennan T, Lee PK, Wind-Rotolo M, Haggerty CM, Kamireddi AR, Liu Y, Lee J, et al. Residual human immunodeficiency virus type 1 viremia in some patients on antiretroviral therapy is dominated by a small number of invariant clones rarely found in circulating CD4+ T cells. J Virol. 2006;80:6441-57.

13. Keele BF, Giorgi EE, Salazar-Gonzalez JF, Decker JM, Pham KT, Salazar MG, Sun C, Grayson T, Wang S, Li H, et al. Identification and characterization of transmitted and early founder virus envelopes in primary HIV-1 infection. Proc Natl Acad Sci USA. 2008;105:7552-7.

14. Salazar-Gonzalez JF, Bailes E, Pham KT, Salazar MG, Guffey MB, Keele BF, Derdeyn CA, Farmer P, Hunter E, Allen S, et al. Deciphering human immunodeficiency virus type 1 transmission and early envelope diversification by single-genome amplification and sequencing. J Virol. 2008:82:3952-70.

15. Casbon JA, Osborne RJ, Brenner S, Lichtenstein CP. A method for counting PCR template molecules with application to next-generation sequencing. Nucleic Acids Res. 2011;39:e81.

16. Fu GK, Hu J, Wang PH, Fodor SP. Counting individual DNA molecules by the stochastic attachment of diverse labels. Proc Natl Acad Sci USA. 2011;108:9026-31.

17. Kinde I, Wu J, Papadopoulos N, Kinzler KW, Vogelstein B. Detection and quantification of rare mutations with massively parallel sequencing. Proc Natl Acad Sci USA. 2011;108:9530-5.

18. Liang RH, Mo T, Dong W, Lee GQ, Swenson LC, McCloskey RM, Woods CK, Brumme CJ, Ho CK, Schinkel J, et al. Theoretical and experimental assessment of degenerate primer tagging in ultra-deep applications of next-generation sequencing. Nucleic Acids Res. 2014;42:e98.

19. Zhou S, Jones C, Mieczkowski P, Swanstrom R. Primer ID validates template sampling depth and greatly reduces the error rate of next generation sequencing of HIV-1 genomic RNA populations. J Virol. 2015;89(16):8540-55. doi:10.1128/JVI.00522-15.

20. Seifert D, Di Giallonardo F, Topfer A, Singer J, Schmutz S, Gunthard HF, Beerenwinkel N, Metzner KJ. A comprehensive analysis of primer IDs to study heterogeneous HIV-1 populations. J Mol Biol. 2016;428:238-50.

21. Boltz VF JR, Shao W, Coomer C, Mellors JW, Kearney MF, Coffin JM. Analysis of resistance haplotypes using primer IDs and next gen sequencing of HIV RNA. In Conference on retroviruses and opportunistic infections; February 23-26, 2015, Seattle, Washington, USA. 2015.
22. Liu HS, Tzeng HC, Liang YJ, Chen CC. Ligation of multiple DNA fragments through uracil-DNA glycosylase generated ligation sites. Nucleic Acids Res. 1994;22:4016-7.

23. Smith C, Day PJ, Walker MR. Generation of cohesive ends on PCR products by UDG-mediated excision of dU, and application for cloning into restriction digest-linearized vectors. PCR Methods Appl. 1993;2:328-32.

24. Gall A, Kaye S, Hue S, Bonsall D, Rance R, Baillie GJ, Fidler SJ, Weber JN, McClure MO, Kellam P, Investigators ST. Restriction of $\mathrm{V} 3$ region sequence divergence in the HIV-1 envelope gene during antiretroviral treatment in a cohort of recent seroconverters. Retrovirology. 2013;10:8.

25. Achuthan V, Keith BJ, Connolly BA, DeStefano JJ. Human immunodeficiency virus reverse transcriptase displays dramatically higher fidelity under physiological magnesium conditions in vitro. J Virol. 2014;88:8514-27.

26. Adey A, Morrison HG, Asan, Xun X, Kitzman JO, Turner EH, Stackhouse B, MacKenzie AP, Caruccio NC, Zhang X, Shendure J. Rapid, low-input, lowbias construction of shotgun fragment libraries by high-density in vitro transposition. Genome Biol. 2010;11:R119.

27. Keys JR, Zhou S, Anderson JA, Eron JJ Jr, Rackoff LA, Jabara C, Swanstrom R. Primer ID informs next-generation sequencing platforms and reveals preexisting drug resistance mutations in the HIV-1 reverse transcriptase coding domain. AIDS Res Hum Retrovir. 2015;31:658-68.

28. Quail MA, Otto TD, Gu Y, Harris SR, Skelly TF, McQuillan JA, Swerdlow HP, Oyola SO. Optimal enzymes for amplifying sequencing libraries. Nat Methods. 2012;9:10-1.

29. Lazinski DW, Camilli A. Homopolymer tail-mediated ligation PCR: a streamlined and highly efficient method for DNA cloning and library construction. Biotechniques. 2013;54:25-34.

30. Palmer S, Boltz V, Maldarelli F, Kearney M, Halvas EK, Rock D, Falloon J, Davey RT Jr, Dewar RL, Metcalf JA, et al. Selection and persistence of non-nucleoside reverse transcriptase inhibitor-resistant HIV-1 in patients starting and stopping non-nucleoside therapy. AIDS. 2006;20:701-10.

31. Tamura K, Stecher G, Peterson D, Filipski A, Kumar S. MEGA6: Molecular Evolutionary Genetics Analysis version 6.0. Mol Biol Evol. 2013;30:2725-9.

\section{Submit your next manuscript to BioMed Central and we will help you at every step:}

- We accept pre-submission inquiries

- Our selector tool helps you to find the most relevant journal

- We provide round the clock customer support

- Convenient online submission

- Thorough peer review

- Inclusion in PubMed and all major indexing services

- Maximum visibility for your research

Submit your manuscript at www.biomedcentral.com/submit
() Biomed Central 